\title{
The effect of entrepreneurship education programmes on the development of self-efficacy, entrepreneurial intention and predictions for entrepreneurial activity
}

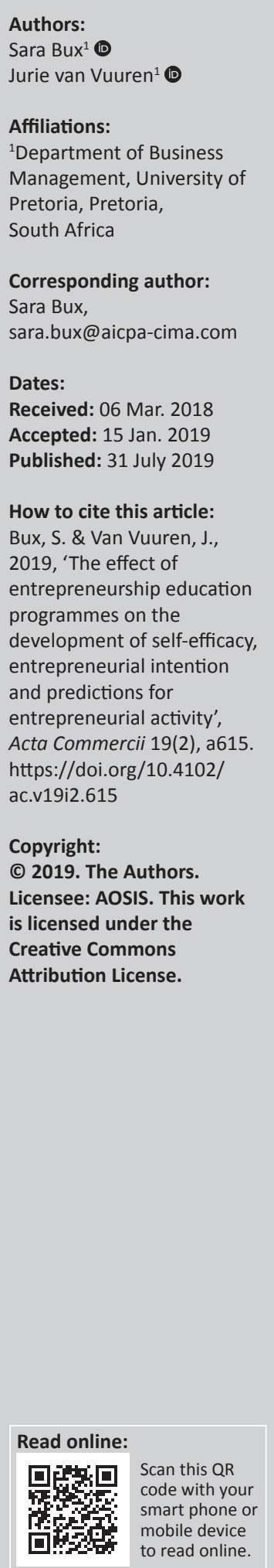

Orientation: South Africa is currently facing a youth unemployment crisis. Confirmation of the problem was situated in our review of the Quarterly Labour Force Survey, Quarter 3, 2015. We found that the 15-24 years age group was most affected where many were neither in employment, education or training. We asked whether the promotion of entrepreneurship among youth could be a potential solution.

Research purpose: Our research sought to investigate whether there existed a correlation between exposure to entrepreneurship education (EE) and the development of self-efficacy in high school South African youth in the age group of 15-18 years. We also investigated if the programme duration would influence the degree to which self-efficacy was developed, and the correlation of self-efficacy with entrepreneurial and entrepreneurial intention as a predictor of entrepreneurial activity.

Motivation for the study: Our motivation stemmed from the belief that the youth unemployment crisis will not be solved by formal employment; that entrepreneurship education needed to be promoted at the school level to address skills mismatches between education and employment creation.

Research design, approach and method: We collected our data through a questionnaire from two samples of students taking the Junior Achievement programme. The study adopted a quantitative approach and adopted the use of a Likert scale questionnaire. Of the 1200 questionnaires distributed, 637 were usable for the short entrepreneurship education programme and 381 were usable for the long entrepreneurship education programme. The purposive sampling technique was adopted. We collected data around the participants' perceptions of selfefficacy post-entrepreneurship education intervention. We used Confirmatory Factor Analysis (CFA) and Structural Equation Model (SEM) to analyse our data. Our tests of reliability and validity by use of CFA and SEM confirmed that we were using a stable model.

Main findings: The research found positive correlations between the items comprising selfefficacy that can be developed through EE. Also, EE of a longer duration had stronger positive correlations with such items.

Practical/managerial implications: We make practical recommendations pertinent to the type of EE schools ought to introduce.

Contribution/value-add: Our research contributed to existing theory about the influence of EE on the development of self-efficacy.

Keywords: entrepreneurial mindset; self-efficacy; entrepreneurship education; South African youth; entrepreneurial intention; entrepreneurial activity.

\section{Introduction}

Youth unemployment is currently an issue in South Africa. Discouraged job seekers are also an issue in South Africa. The situation is made worse by the fact that the formal sector cannot create jobs nor absorb job seekers at a rate that will meaningfully contribute to alleviation of the issues of unemployment or discouraged job seekers. In seeking to address the issue, the South African government has endeavoured to promote entrepreneurship as a means of addressing the issue of youth unemployment. Whilst this is not a unique approach, Bignotti (2013) suggests that there is limited study in South Africa that allows us to meaningfully engage with the government's endeavoured approach and to shift mindsets of South African youth from job seeking to job creating.

Whilst there is good reason for South Africa to consider entrepreneurship as an approach to addressing youth unemployment, there are other related benefits in considering the 
entrepreneurship approach. One of these includes enablement of its youth to become globally competitive and therefore more employable; another is addressing the issue of the inability of the formal sector to create jobs or absorb job seekers at the required rate to contribute meaningfully to their participation in the economy. However, in its annual report of 2011, the National Treasury (NT) acknowledges the youth unemployment issue and suggests that reform of the situation requires short- and long-term approaches: some of these approaches would include labour demand and the provision of education that addresses issues such as quality education and scarce skills in this country.

There is another and more burning reason for the advocacy for entrepreneurship in South Africa. In its recently released report, Poverty Trends in South Africa (2017), Statistics South Africa (Stats SA) asserts that from 2011 to 2015, the percentage of people living in poverty increased year on year to an alarming $55.5 \%$ in 2015 . This is particularly a concern for South Africa given that poverty eradication is the top ranked Sustainable Development Goal (SDG) as identified by the United Nations. Being a member state, South Africa is obliged to deliver on this number one SDG.

Of the three ways South Africa (SA) is doing so, growing entrepreneurship was cited as one. The belief was that entrepreneurship was an appropriate approach, given that it enables people to provide for themselves and thus eradicate poverty. Whilst South Africa has a number of programmes in place to empower and enable people to engage in entrepreneurship, the low uptake rate and low success rate remain an issue and do not contribute meaningfully to the question of poverty eradication and the SDG. The various industry sectors in South Africa are coming together and working collaboratively to address the issue of youth unemployment and poverty eradication.

The NT report concluded that (relevant) skills deficiencies contributed to that gap and that the provision of quality education and skills development should become a priority for government. Whilst government does prioritise the matter, and amidst other things does attempt to implement education interventions to raise the quality of basic education, re-engage dropouts with the education system and provide an environment that cultivates academic, technical and vocational skills, those interventions will take time to yield impact and will require monitoring and evaluation. Inherent to such education interventions, entrepreneurship education has a vital role to play. The NT is also playing a part in this collaboration. Whilst the business sector finds ways to collaborate, the NT is addressing the issue from the perspective of education. Key to its question of education, the NT posed some critical questions relating to quality of basic education, youth who have dropped out of education (not in education) and then the issue of the introduction of entrepreneurship education.

In his study, Urban (2016) suggested that entrepreneurship is one of the most important tools that we have to solve the unemployment problem in South Africa. Whilst he states this, he also goes on to elaborate on the significance of developing an enabling environment for entrepreneurship and the development of the entrepreneurial mindset in South Africans. By examining the Angolan and Mozambican economies, Urban states that a critical mass of entrepreneurs is required in an economy to make a difference to the issues of unemployment. He also states that a good education is required to drive the goal of developing a significant enough quantity of entrepreneurs to begin to address the issue.

In a study that examined key influence groups to address the issue of poverty eradication, it was found that youth development is a key priority group (De Berg \& Eimer 2014:176-177). This has implications for South Africa and more so in light of the finding of the International Labour Organization (ILO) (2009) that youth unemployment becomes a societal burden. Another significant finding of the ILO study is that unless youth are absorbed into economic participation early on, their opportunities for economic participation for life are hampered. The ILO report also states that education and training investment is a waste if it does not enable youth to become economically active and participate constructively in economic development. Bearing this in mind, we believe that entrepreneurship education can make a significant difference to South Africa's youth, and we therefore sought to understand what can enable youth to participate constructively in South Africa's economy.

Through examination of prior research, we have established and highlighted that entrepreneurship is being emphasised in a number of contexts in South Africa (business and government). We believe, in addition, that a number of studies have shown that there exists a correlation between entrepreneurship and education as well as entrepreneurship and poverty eradication; thus, it is imperative that South Africa begin to implement entrepreneurship education in school no later than high school. The authors also believe that schools have an important role to play in the creation of the entrepreneurial mindset and entrepreneurship as a career choice (Aslam, Awan \& Khan 2012:115). However, Steenekamp, Van der Merwe and Athayde (2011) point out that the relationship between entrepreneurship education and entrepreneurship as a career choice requires more study and description in the South African context. They state that more information is required to fully understand the kind of education interventions required to address the employability of youth exiting school.

Given this reality, we accepted that entrepreneurship is a mindset, sought to define quality entrepreneurship education and asked the question, 'What are key components of quality entrepreneurship education?' We were specifically interested in the component of self-efficacy, which we believed to be a critical component in entrepreneurship education in South Africa. Our belief was shaped by findings by Herrington (2006), who stated that potential entrepreneurs in South Africa lacked the mindset and skills to become true entrepreneurs. Herrington's finding suggested to us that we had to do more to investigate what could be done to boost individual beliefs and competencies. 
We thus started by examining academic literature on entrepreneurial behaviour, attitudes and intentions by looking at the influence of self-efficacy in unlocking future entrepreneurs. In doing so, we accepted that self-efficacy is becoming a wellknown link between entrepreneurship and entrepreneurial intention because entrepreneurs' success is reliant on their entrepreneurial intention and whether they believe in their abilities to perform as an entrepreneur (Moos 2016:469).

\section{Literature review}

Our primary assumption was that entrepreneurship education fosters self-efficacy. We also assumed that the duration of the entrepreneurship education received would determine the degree to which the perceptions of self-efficacy are developed. The secondary assumption was that perceptions of self-efficacy would influence entrepreneurial intention and entrepreneurial behaviour.

In a full research, Bux (2017) noted that for South African youth, a mindset that includes the general constructs of the entrepreneurial mindset, namely self-efficacy, an inner locus of control and the need for achievement, would hold them in good stead. In this article, we will specifically consider the influence of entrepreneurship education on self-efficacy, entrepreneurial intention and predictions for entrepreneurial behaviour.

\section{Entrepreneurship as a learned behaviour}

For the purpose of this article, we examined Ajzen's theory of planned behaviour (TPB) (1991) as we sought to describe the influence of entrepreneurship education on selfefficacy, entrepreneurial intention and entrepreneurial activity.

We examined empirical studies from 1996 to 2014 and conducted cross-country profiles by location and state of development. Our examination included Kolvereid (1996), Kreuger, Reilly and Carsrud (2000), Douglas and Shepherd (2002), Souitaris, Zerbinati and Al-Laham (2007), Kuratko (2005), Lin andChen (2010), Bidin, Shamsudin and Othman (2012), Barua (2013), Karali (2013) and Alain and Linan (2014). Through this examination, we were able to establish support for the adoption of the TPB and that entrepreneurship could become a learnt behaviour.

\section{Self-efficacy and resilience to remain entrepreneurially intent}

We also wanted to establish that self-efficacy was a significant component to be included in a successful entrepreneurship education intervention for South African youth. We examined Bandura's social cognitive theory (SCT) (1986), which cites self-efficacy as one of the most important variables that influence people's beliefs about their capability to perform. Bandura suggests that self-efficacy is demonstrated by belief in one's own ability, that is, self-confidence to control one's own success, which does not depend on others, a high degree of endurance and the ability to continue wilfully, in spite of setbacks or objections.

We went on to examine studies that validated our belief that self-efficacy would lead to better performance in tasks. What we wanted to establish was that advocacy for self-efficacy within entrepreneurship education would indeed bear relevance and influence on South African youth as future entrepreneurs.

We conducted a broad review of related research, which included the following: Bandura (1997), Tenaw (2013), Mahyuddin et al. (2006), Collins (1982) and Tsang, Hui and Law (2012). There was general support for the importance of self-efficacy and the ability to perform. We found this of particular significance when we considered the reality of the immature entrepreneurial ecosystem in South Africa. We were satisfied that to succeed in such a reality, a person's belief in self would need to be emphasised within entrepreneurship education, which offers an opportunity to repeatedly engage in a task and develop confidence in one's ability to perform such a task successfully in the future, which speaks to enactive mastery (Bux 2017).

We went on to assess the findings of other studies, which included the following: Pajares (2005); Zhao, Seibert and Hills (2005); Drnovsek, Wincent and Cardon (2009); Urban (2011); Camp (2011); Malebana and Swanepoel (2014); Olakitan (2014); Shinaar, Hsu and Powell (2014); Kurczewska and Bialek (2014); Hermawan, Soetjipto and Rahayu (2016) and Pfeifer, Sarlija and Susac (2016). We were satisfied that this broad range of studies across a number of years found and continued to establish a generally positive relationship between entrepreneurship education, self-efficacy and entrepreneurial intent.

\section{Entrepreneurship education theory}

Given our belief that entrepreneurship can be taught, we had to validate that it was a fair belief. We thus examined prior research, which included Fayolle (2013) and Kozlinska (2014). We found that there was need to show a linkage with entrepreneurship education and a suitable theory of teaching and learning. In our examination of cognitive educational theory (CET), we found it to be suitable. An examination of Neck and Greene (2011) suggested that cognitive theorists focus on the cognitive processes of individuals, where if we considered a process of decision-making to engage in entrepreneurial activity, the process would include attitudes, not limited to but including self-efficacy, which we found to intersect well with SCT.

Given that we were interested in the orientation towards entrepreneurship as a career choice, we examined studies that might provide more insights in our interest. Our examination pointed us to the pattern-recognition perspective, Baron (2006) and Krueger (2003) demonstrating support for how education could be structured so as to equip students to manage their mental processes to think and enact processes linked with entrepreneurship. We were 
thus satisfied that CET could ground our belief that education has the power to influence people choosing entrepreneurship as a career path, to equip them with the required competences and to develop from novices to experts (Krueger 2003:34).

We were also interested to review other research that would generally validate CET and the belief that one can be taught entrepreneurship through the appropriate learning intervention. We found such validation in the research of Sarasvathy and Venkataraman (2011); Fayolle (2013); Kuratko (2005); Kyro (2005); Gibb (2005); Fayolle and Gailly (2008); Lundstrom and Stevenson (2001); Gormon, Hanlon and King (1997); Viviers, Soloman and Venter (2013); Garud and Giuliani (2013); Rideout and Gray (2013); Martin, McNally and Kay (2012); Van Vuuren (2014); Sanchez (2013); Morris et al. (2013) and Antonites and Govindasamy (2013). We were thus satisfied that entrepreneurship could be taught as a learned behaviour.

We still needed to understand what successful, quality entrepreneurship education for South African youth would look like. We examined the training model as found in Botha, Van Vuuren and Kunene (2015). This examination directed the questions we would ask our sample groups.

\section{The theoretical model within this research}

Our belief is that too few South African youth are currently exposed to entrepreneurship education. Consequently, too few have developed an entrepreneurial mindset and engage in entrepreneurship. We posited that the introduction of mandatory entrepreneurship education for South African learners in the age group 15-18 (Grades 10-12 in basic education) would instil in them the self-efficacy to consider entrepreneurship as a career choice. We asked questions to understand:

- the influence of a short entrepreneurship education intervention on self-efficacy

- the influence of a long entrepreneurship education intervention on self-efficacy

- the difference, if any, that the duration of an entrepreneurship education intervention would exert on self-efficacy, entrepreneurial intentions and entrepreneurial activity.

We conducted an assessment of entrepreneurship education intervention on15-18-year-olds in basic education, Grades 10-12. Our objective was to describe if they developed self-efficacy through this intervention. We wanted to describe their perceived development in the various constructs of self-efficacy, and we wanted to describe the difference, if any, of the influence of duration of the intervention on self-efficacy.

We linked this to the following hypotheses (graphically represented in Figure 1):

$\mathbf{H}_{1}$ : Those who participate in the longer entrepreneurship education intervention will report higher increased levels of selfefficacy relative to those who participate in the shorter entrepreneurship education intervention.

$\mathbf{H}_{0}$ : Participants who access the short and long entrepreneurship education intervention will report increased levels of selfefficacy, and intervention duration will have no influence.

$\mathbf{H}_{2}$ : Participants in both interventions will report positive perceptions of enabling anything to become an entrepreneur.

$\mathbf{H}_{0}$ : Participants in both entrepreneurship education interventions will report negative perceptions of doing anything to become an entrepreneur.

$\mathbf{H}_{3}$ : Participants in both interventions will report positive perceptions of having acquired the required knowledge and skills to become an entrepreneur.

$\mathbf{H}_{0}$ : Participants in both interventions will report negative perceptions of having acquired the required knowledge and skills to become an entrepreneur.

$\mathbf{H}_{4}$ : Participants in both interventions will report positive perceptions of seeking further knowledge and skills through other entrepreneurship education if needed.

$\mathbf{H}_{0}$ : Participants in both interventions will report negative perceptions of seeking further knowledge and skills through other entrepreneurship education if needed.

$\mathbf{H}_{5}$ : Participants in both interventions will report positive perceptions of self-confidence to succeed in the future.

$\mathbf{H}_{0}$ : Participants in both interventions will report negative perceptions of self-confidence to succeed in the future.

$\mathbf{H}_{6}$ : Participants in both interventions will report positive perceptions of accurately evaluating their strengths and weaknesses.

$\mathbf{H}_{0}$ : Participants in both interventions will report negative perceptions of accurately evaluating their strengths and weaknesses.

$\mathbf{H}_{7}$ : Participants in both interventions will report positive perceptions of all things, even failure, as an opportunity to improve.

$\mathbf{H}_{0}$ : Participants in both interventions will report negative perceptions of all things, including failure, as an opportunity to improve.

\begin{tabular}{|c|c|c|c|c|}
\hline $\begin{array}{l}\text { Entrepreneurship } \\
\text { education programme }\end{array}$ & Programme duration & $\begin{array}{l}\text { Self-efficacy: } \\
\text { - Anything to be an entrepreneur }\end{array}$ & $\begin{array}{l}\text { Entrepreneurial } \\
\text { intention }\end{array}$ & Entrepreneurial activity \\
\hline & & $\begin{array}{l}\text { - Acquire knowledge and skills } \\
\text { - Seek further education } \\
\text { - Confidence } \\
\text { - Evaluate strengths and weaknesses } \\
\text { - Perceive even failure as opportunity } \\
\text { to improve }\end{array}$ & & \\
\hline
\end{tabular}

FIGURE 1: Conceptual model. 


\section{Research methodology}

Our ontological assumption was that intentions can enable action and, more specifically, that if more South African youth received entrepreneurship education, it would create a critical mass of entrepreneurs and shift reliance from an already overburdened social system (World Bank 2017). Moreover, given the immature South African entrepreneurial state, a good starting point to address this immaturity would be the introduction of mandatory high school entrepreneurship education. In addition, our epistemological assumption was that intentions and/or actions relate to a mental or cognitive state. We thus believed that the enablement of the entrepreneurial mental state can be achieved through appropriate education interventions.

We thus developed our research paradigm. Table 1 illustrates our thinking.

Our article adopted a positivist paradigm and deductive reasoning. We aimed to address past research methodological limitations by ensuring a good sample size, implementing two entrepreneurship education interventions of varying duration and engaging participants who were in an unchanging reality (in the age group 15-18 in Grades 10-12 in basic education). We aimed to quantify (adopting a quantitative approach) those constructs that would foster self-efficacy within the entrepreneurship education interventions to be able to describe the relationships among those factors.

Our cross-sectional study engaged 15-18-year-olds in Grades 10-12 in basic education in a one-time interaction.

Our study population comprised all 15-18-year-olds in Grades 10-12 in basic education in 2015 taking a Junior Achievement South Africa (JASA) entrepreneurship education intervention in 2015. They could have been taking either the short or long intervention. The population was 3000 . Our eligibility criteria specified that our population had to be 15-18-year-olds in Grades 10-12 in basic education in 2015 taking the JASA intervention and willing to participate in our study.

We constituted two random samples: 800 in the shorter intervention and 400 who attended the longer intervention.

TABLE 1: Research paradigm.

\begin{tabular}{ll}
\hline Our purpose & $\begin{array}{l}\text { To investigate the influence of entrepreneurship education on } \\
\text { self-efficacy }\end{array}$ \\
\hline Ontology & - Realist ontology. \\
& - Human behaviour is an earned reality. \\
- Human beings construct meaning of their individual reality. & - Human beings' knowledge and experience can determine their \\
& reality.
\end{tabular}

We piloted and collected our data via a questionnaire from these samples. Following from that, we tested and found our questionnaire to be reliable, valid and stable.

We selected the JASA intervention because it was accessible in urban and rural schools across South Africa. The learning outcomes closely matched the competencies, skills and knowledge components we found in the Botha et al. model.

Through the instrument, we collected data around the participants' perceptions of self-efficacy post-entrepreneurship education intervention. We framed our items using the Bandura standardised scale of self-efficacy.

Having read extensively (Bandura 2006; Boyer et al. 2000; Holden 1991; Holden et al. 1990; Moritz et al. 2000; Multon, Brown \& Lent 1991; Sadri \& Robertson 1993; Stajkovic \& Luthans 1998), we saw the need to specify our entrepreneurial domain and adapted the Bandura standardised scale to suit our purpose.

We also gathered information around the participants' entrepreneurial intent and/or entrepreneurial activity in the next 3-5 years post attending the entrepreneurship education intervention. We adapted our items from the standardised eScan scale. Whilst there is dissention over the specific factors that can confirm entrepreneurial intention and entrepreneurship activity, in our article, we agreed to accept the eScan scale as a fair indicator of such.

From our preliminary data examination process, we found V20 and V34 to be unstable and thus eliminated those. For Sample 1, we had 637 usable questionnaires and 381 for Sample 2.

We used the Likert scale in our questionnaire, where: not at all $=1$; somewhat $=2 ;$ moderately $=3$; to a large extent $=4$; completely $=5$.

\section{Statistical analysis}

Statistical Analysis System was used to run frequency tables, factor analysis and test reliabilities. Confirmatory factor analysis (CFA) was used to test whether the measured variables tested the constructs used. The structural equation model (SEM) was used to assess the proposed measurement model. Analysis of moment structures was used for SEM path analysis.

Confirmatory factor analysis allowed us to demonstrate that the six factors we linked to self-efficacy were clear to identify. Our model fit indices are illustrated in Figure 2.

The Cronbach's alpha was used to test internal reliability; that is, the strength of the measuring items in measuring the construct. In exceeding 0.7, our Cronbach's alpha was deemed satisfactory. In achieving a value of greater than 0.6 , our composite reality was deemed satisfactory. See Table 2 for all factor loadings. 
We also ran a PROC CORR test to ensure that our Cronbach's alpha was reliable. Our factor loadings are presented in Table 3.

We used the SEM to measure the relationships among the latent and observed variables through the analysis of covariance among observable variables. It formed the basis for estimating a structural relationship that would describe the relationship of constructs stated in the questions (Bux 2017).

In our study, we accepted that the constructs of self-efficacy cannot be observed directly.

In using the SEM, we were able to represent the causal represented by regression equations and the structural relations to generate a robust conceptual framework for the study. We tested the hypothesised model statistically and

\begin{tabular}{|c|c|c|c|}
\hline $\begin{array}{l}\text { Exogenous } \\
\text { variable }\end{array}$ & $\begin{array}{l}\text { Dependant } \\
\text { variable }\end{array}$ & $\begin{array}{c}\text { Construct } \\
V=6\end{array}$ & $\begin{array}{l}\text { Standardised } \\
\text { regression weight }\end{array}$ \\
\hline \multirow{6}{*}{$\begin{array}{l}\text { Entrepreneurial } \\
\text { education } \\
\text { programme }\end{array}$} & \multirow{6}{*}{ Self-efficacy } & V11 & 0.62 \\
\hline & & V12 & 0.62 \\
\hline & & V13 & 0.43 \\
\hline & & V14 & 0.62 \\
\hline & & V15 & 0.6 \\
\hline & & V16 & 0.6 \\
\hline \multicolumn{2}{|l|}{ Model fit indices } & & \\
\hline CMIN & 1082.27 & & \\
\hline DF & 367 & & \\
\hline CMIN/DF & 2.95 & & \\
\hline$p$-value & 0.00 & & \\
\hline GFI & 0.9 & & \\
\hline RMSEA & 0.51 & & \\
\hline
\end{tabular}

CMIN, Chi-square statistics; RMSEA, root mean square error of approximation; DF, degrees of freedom; GFI, goodness-of-fit index.

FIGURE 2: Model fit indices.

TABLE 2: Cronbach alpha and composite reliability results.

\begin{tabular}{lccc}
\hline Variable & Raw CA & $\begin{array}{c}\text { Standardised CA } \\
>0.7\end{array}$ & $\begin{array}{c}\text { Reliable } \\
\text { Reliable }\end{array}$ \\
\hline Self-efficacy & 0.72 & 0.73 & - \\
11-Anything to be an entrepreneur & - & - & 1.00 \\
12-Acquire knowledge and skills & - & - & 14.02 \\
13-Seek further knowledge & - & - & 10.36 \\
14-Confidence & - & - & 14.11 \\
15-Evaluate strengths and weaknesses & - & - & 13.55 \\
$\begin{array}{l}\text { 16-Perceive all things, even failure, as } \\
\text { opportunity to improve }\end{array}$ & - & - & 13.64 \\
\hline
\end{tabular}

CA, Cronbach's alpha; CR, composite reliability. found an acceptable relationship among all variables, which was also consistent with the data.

In considering Little's (2013) statement that the various indices of model adequacy, especially the chi-square $\left(\chi^{2}\right)$ goodness-of-fit test, indicate the degree to which the pattern of fixed and free parameters (which shows the relationship between variables) in the model is consistent with the pattern of variances and covariances from a set of observed data. We used the maximum likelihood index (MLI) method for model estimation and testing of model fit. Our MLI was deemed satisfactory. Our model could show a unique value for each parameter, which should not exceed 1.00. Our model satisfied the requirement.

As suggested by Byrne (2001) that the appropriate input of data in SEM research is covariance matrix relating to all variables specified in the hypothesised model, we adopted the covariance matrix because it allowed us to consider multivariate relationships.

Each path in the structural model between the latent variables represents a specific hypothesis. Hypotheses are usually tested in the form of a null hypothesis $\left(\mathrm{H}_{0}\right)$, where no relationship exists or an estimate equals zero. In this study, where $p \leq 0.1$, we reject the null hypotheses.

The levels of significance (represented in Table 4) that were employed in the current study were $\leq 0.1$. The lower the significance level, the more the data must deviate from the null hypothesis (estimate equals zero). In this study, a significance level less than $0.1(p \leq 0.1)$ was considered a weak significance level; however, there was support that that value could be deemed an acceptable significance level (Byrne 2010:68; Creswell 2007:123,).

We implemented tests of reliability and validity throughout by use of the CFA and SEM. Being satisfied that those were stable, we ran the CFA on each of the constructs.

\begin{tabular}{|c|c|c|c|c|}
\hline Variable & Estimate & Standard error & Capability ratio & $P$ \\
\hline V11 & 1 & - & - & - \\
\hline $\mathrm{V} 12 \longrightarrow \cdots \mathrm{SE}$ & 0.85 & 0.06 & 14.02 & $* * *$ \\
\hline V13 $4 \cdots$ SE & 0.77 & 0.07 & 10.36 & $* * *$ \\
\hline V14 $\downarrow \cdots$ SE & 0.69 & 0.05 & 14.11 & $* * *$ \\
\hline V15 $\longrightarrow$ SE & 0.73 & 0.05 & 13.55 & $* * *$ \\
\hline V16 $\cdots$ SE & 0.86 & 0.06 & 13.64 & $* * *$ \\
\hline
\end{tabular}

SE, self-efficacy.

TABLE 3: PROC CORR results. Self-efficacy 6 Variables: V11, V12, V13, V14, V15, V16. Cronbach coefficient Alpha with deleted Variable (where applicable).

\begin{tabular}{|c|c|c|c|c|c|}
\hline \multirow[t]{2}{*}{ Deleted variable } & \multicolumn{2}{|c|}{ Raw variables } & \multicolumn{3}{|c|}{ Standardised variables } \\
\hline & Correlation with total & Alpha & Correlation with total & Alpha & Label \\
\hline V11 & 0.50 & 0.67 & 0.50 & 0.69 & V11 \\
\hline V12 & 0.51 & 0.67 & 0.51 & 0.69 & V12 \\
\hline V13 & 0.35 & 0.72 & 0.35 & 0.73 & V13 \\
\hline V14 & 0.49 & 0.68 & 0.50 & 0.69 & V14 \\
\hline V15 & 0.46 & 0.68 & 0.47 & 0.70 & V15 \\
\hline V16 & 0.49 & 0.67 & 0.50 & 0.70 & V16 \\
\hline
\end{tabular}




\section{Ethical considerations}

Ethical clearance to conduct the study was obtained by the Research Ethics Committee of the University of Pretoria, Faculty of Economic and Management Sciences.

\section{Discussion of results}

We ran the CFA on self-efficacy and illustrate the fit indices in Figure 3.

Being satisfied with the model fit indices, we conducted the CFA on self-efficacy on six items. The standardised regression weighting was above 0.5 for each item except for V13. The $f$-value was thus satisfactory for all items being 0.5 and above except for V13. This suggests that there is a significant relationship between the set of predictors and the dependent variable, except for in V13.

Our data fitted the model acceptably as demonstrated by the factor CFA loadings in Table 5.

The CFA constructs were stated on the questionnaire as reflected in Table 6. The full primary research may be accessed online and at the University of Pretoria repository (Bux 2017).

\section{Discussion on self-efficacy}

Our participants' completion rate for the self-efficacy construct and its six factors may be reported as $97 \%$ for the short entrepreneurship education intervention and $99 \%$ for the longer entrepreneurship education intervention. We observed that most of the responses clustered around 4 and 5 . We also found that there was evidence from our participants' responses (97\% and 99\% respectively for the short and long entrepreneurship education intervention) to support the view that the participants had positive perceptions of their self-efficacy post-intervention. It was of notable interest to us that our finding generally concurred with the views of other research we had reviewed in this field. We noted our finding with particular interest for the South African context, where, given the immature state of entrepreneurship, self-efficacy may well be one of the key factors that would motivate and encourage youth to continue in the face of an immature state of entrepreneurship.

Further, we found that our participants who engaged in the long entrepreneurship education intervention recorded

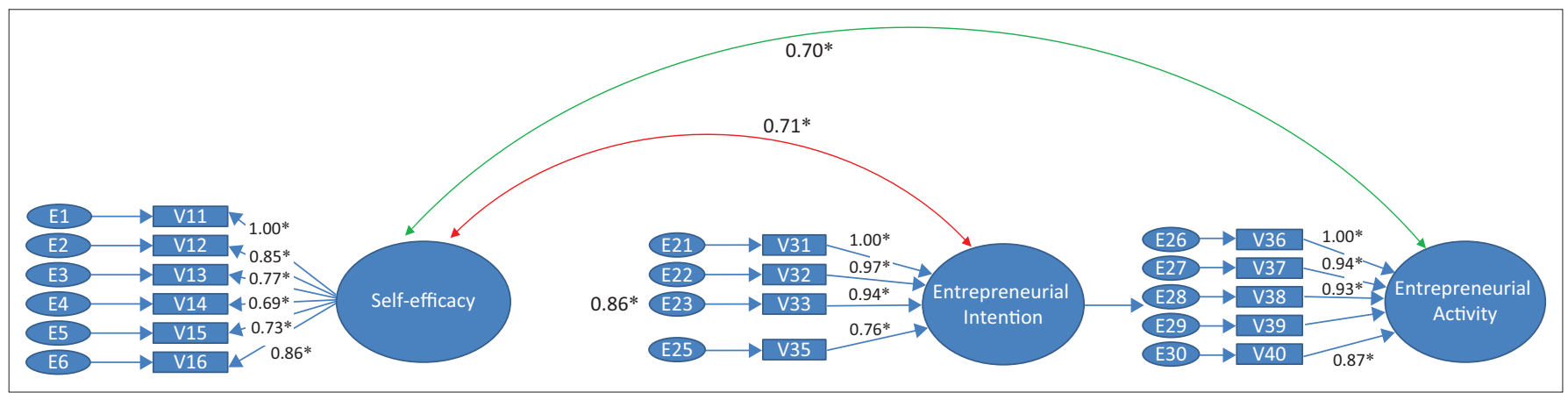

FIGURE 3: Confirmatory factor analysis on participants' perceived self-efficacy.

TABLE 5: Self-efficacy factor loadings.

\begin{tabular}{lll}
\hline Self-efficacy & Factor description & Loading \\
\hline 11 & Anything to be an entrepreneur & 1.00 \\
12 & Acquired knowledge and skills to be an entrepreneur & 0.85 \\
13 & Seek further knowledge outside the programme, if needed & 0.97 \\
14 & Confidence to be an entrepreneur & 0.69 \\
15 & Skill to accurately evaluate my strengths and weaknesses \\
16 & Perceive all things, even failure, as an opportunity to improve \\
\hline
\end{tabular}

Self-efficacy $\langle------>$ Entrepreneurial Intention $=0.71$.

Self-efficacy $\langle----->$ Entrepreneurial Activity $=0.70$.

TABLE 6: Questions relating to self-efficacy.

\begin{tabular}{|c|c|c|c|c|c|c|c|}
\hline No. & Question & Rank 1 & Rank 2 & Rank 3 & Rank 4 & Rank 5 & Variable \\
\hline 10 & I am prepared to do anything to become an entrepreneur. & 1 & 2 & 3 & 4 & 5 & V11 \\
\hline 11 & $\begin{array}{l}\text { I believe that I have acquired the required knowledge and skills to become an entrepreneur } \\
\text { through the programme. }\end{array}$ & 1 & 2 & 3 & 4 & 5 & V12 \\
\hline 12 & $\begin{array}{l}\text { I will seek further knowledge and skills through other entrepreneurship education if the } \\
\text { programme does not fulfil this need. }\end{array}$ & 1 & 2 & 3 & 4 & 5 & V13 \\
\hline 13 & The programme has taught me to have confidence in myself to succeed in the future. & 1 & 2 & 3 & 4 & 5 & V14 \\
\hline 14 & The programme has taught me to accurately evaluate my strengths and weaknesses. & 1 & 2 & 3 & 4 & 5 & V15 \\
\hline
\end{tabular}

Note: Questions 10 to 15 test measures of self-efficacy; this reflects the belief in one's own ability, that is, self-confidence. Successful entrepreneurs are usually convinced that they can bring every activity to a successful end. Moreover, they feel that they can control their own success, which does not depend on others. 
higher perceptions of self-efficacy compared to our participants who engaged in the short entrepreneurship education intervention. This was corroborated by our descriptive statistics, which measured $p<0.1$, and by our mean difference, which measured 0.1414 . We noted that though the numerical difference was small, there was a difference to support our hypothesis as regards the influence of intervention duration on the development of self-efficacy.

In our graph in Figure 4, we were particularly interested in the differential by percentage recorded at scale 5 when comparing the participants who engaged in the short and long entrepreneurship education intervention. We found the graph to be informative in showing the full ranking of scaled scores.

We also considered it important to include the descriptive statistics as another lens of interpretation. We present those statistics in Table 7.

In finding that there was evidence to support our views that any engagement with an entrepreneurship education intervention will positively influence perceptions of selfefficacy and that the duration of the intervention will influence the degree to which these positive perceptions of self-efficacy are experienced, we were able to make the following conclusions. We concluded and accepted the following hypothesis:

$\mathbf{H}_{1}$ : Those who participate in the longer entrepreneurship education intervention will report higher increased levels of selfefficacy relative to those who participated in the shorter entrepreneurship education intervention.

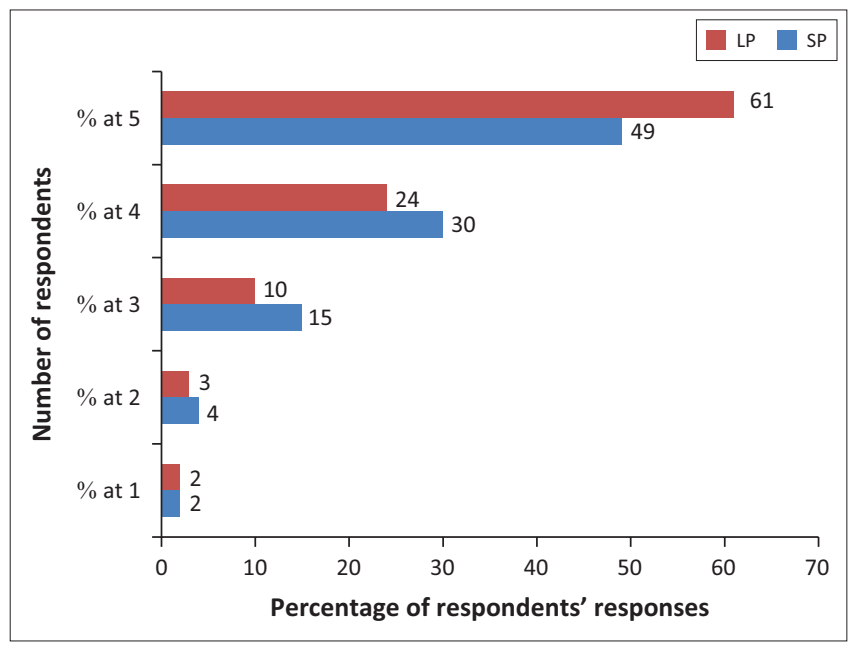

FIGURE 4: Influence on self-efficacy by programme duration.
We concluded that our research here in South Africa with 15-18-year-olds concurred generally with the findings of other research (Bandura 1997; Camp 2011; Collins 1982; Mahyuddin et al. 2006; Tenaw 2013; Tsang, Hui and Law 2012; Urban 2011) conducted around the world, including South Africa. We concluded that any entrepreneurship education intervention will promote positive perceptions of self-efficacy. We also concluded that the duration of the intervention will influence the degree to which those perceptions are experienced; increasing the duration of the intervention will result in increased positive perceptions of self-efficacy. We concluded that if South African youth were to be encouraged to consider entrepreneurship as a career choice, they should first have belief in their capability before actually being enabled with the capability. Our reason for this interest stemmed from our knowledge of the immature state of entrepreneurship in South Africa and the related challenges of practically engaging in entrepreneurship. This we found to be interesting for further discussion and expansion on other recommendations.

In the interest of understanding the correlation between positive perceptions of self-efficacy and entrepreneurial intentions, we ran a CFA (see Figure 5). Our CFA showed acceptable levels of data fit to the measurement model.

We conducted our CFA on our five factors. Our results for regression exceeded 0.5 , indicating acceptable data fit to the model. We noted that our factor represented by V34 was below 0.5 , measuring at 0.22 . We identified this as an outlier and left V34 out of the model. In so doing, we found our $f$-value to be statistically significant where $p<0.5$ (Little 2013): we were then satisfied that there was a significant relationship between our predictors and the dependent variable.

Our CFA factor loadings are reflected in Table 8 or relationship between self-efficacy and entrepreneurial intention.

We worded our CFA factors as outlined in Table 9. We included V34 for the reader's reference. Our assumption was that the ambiguous wording of V34 might have contributed to it being identified as an outlier.

\section{Discussion on entrepreneurial intention}

Our participants' completion rate for the entrepreneurial intention construct and its five factors may be reported as $97 \%$ for the short entrepreneurship education intervention

TABLE 7: Descriptive statistics of increase in self-efficacy by programme duration.

\begin{tabular}{|c|c|c|c|c|c|c|c|c|}
\hline$\overline{\mathrm{V} 1}$ & $N$ & Mean & $\begin{array}{l}\text { Standard } \\
\text { deviation }\end{array}$ & Standard error & $t$-value & $\operatorname{Pr}>t$ & Minimum & Maximum \\
\hline Long programme (LP) & 383 & 4.37 & 0.59 & 0.03 & - & - & 1 & 5 \\
\hline Short programme (SP) & 634 & 4.22 & 0.64 & 0.02 & - & - & 1 & 5 \\
\hline Diff (1-2) Pooled & - & 0.14 & 0.62 & - & 3.51 & 0.0005 & - & - \\
\hline Diff (1-2) Satterthwaite & - & 0.14 & - & - & 3.58 & 0.0004 & - & - \\
\hline
\end{tabular}




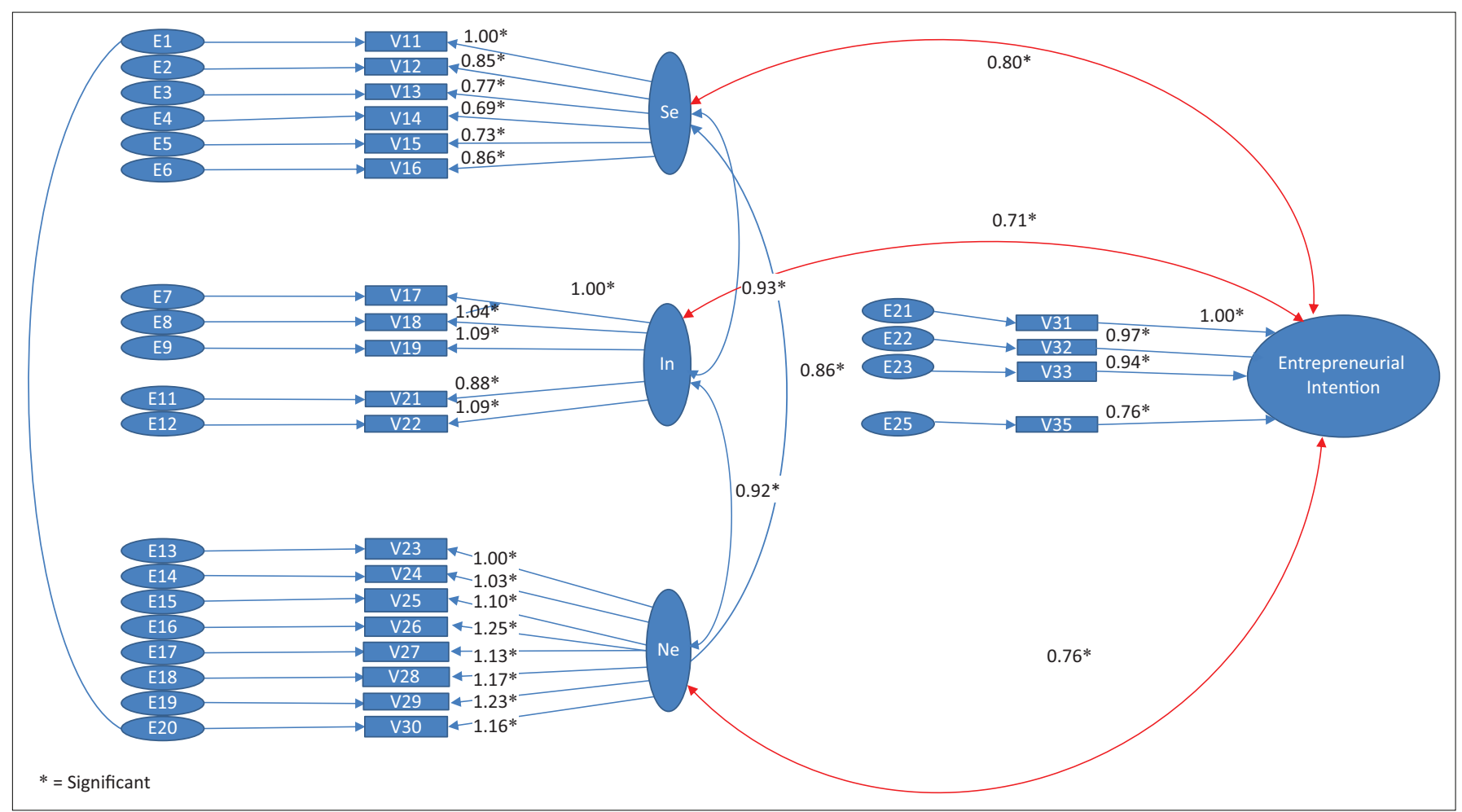

Se, self-efficacy; Lo, locus of control; Ne, need for achievement.

FIGURE 5: Confirmatory factor analysis on entrepreneurial intention.

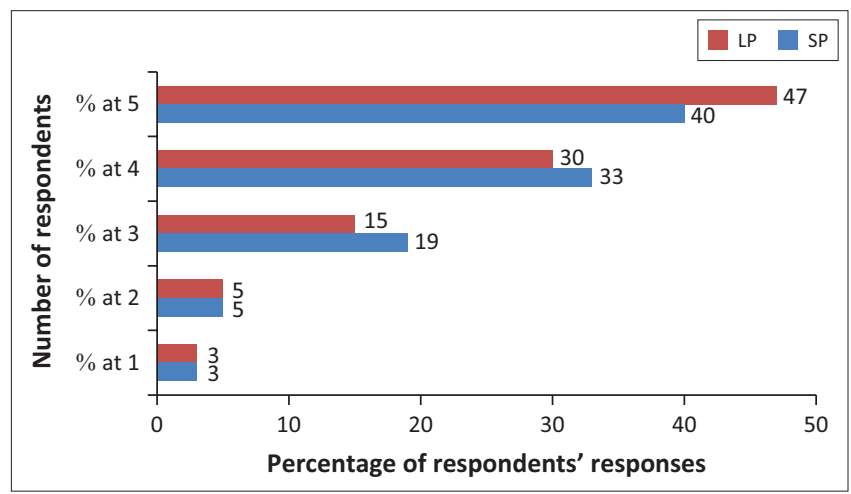

LP, long programme; SP, short programme.

FIGURE 6: Influence on entrepreneurial intention by programme duration.

TABLE 8: Entrepreneurial intention factor loadings.

\begin{tabular}{llc}
\hline Variable & Factor description loading & Loading \\
\hline 31 & I have the competencies to be an entrepreneur & 1.00 \\
32 & I have the skills to be an entrepreneur & 0.97 \\
33 & I have the knowledge to be an entrepreneur & 0.94 \\
34 & Want to be an entrepreneur because I have no other means & 0.42 \\
35 & I spot opportunities to be an entrepreneur & 0.76 \\
\hline
\end{tabular}

Self-efficacy $<------>$ Entrepreneurial Intention $=0.71$.

and $99 \%$ for the longer entrepreneurship education intervention. We observed that most of the responses gathered across the short and long interventions clustered around 4 and 5 (see Figure 7). We also found that there was evidence from our participants' responses (97\% and 99\% respectively for the short and long entrepreneurship education interventions) to support the view that the participants experienced positive influence on their intent to be entrepreneurial. We did find that the duration of the
TABLE 9: Questions relating to entrepreneurial intention.

\begin{tabular}{|c|c|c|c|c|c|c|c|}
\hline No. & Questions & $\begin{array}{c}\text { Rank } \\
1\end{array}$ & $\begin{array}{c}\text { Rank } \\
2\end{array}$ & $\begin{array}{c}\text { Rank } \\
3\end{array}$ & $\begin{array}{c}\text { Rank } \\
4\end{array}$ & $\begin{array}{c}\text { Rank } \\
5\end{array}$ & Variables \\
\hline 34 & $\begin{array}{l}\text { I want to be an entrepreneur } \\
\text { because I have the competencies to } \\
\text { become one. }\end{array}$ & 1 & 2 & 3 & 4 & 5 & V31 \\
\hline 35 & $\begin{array}{l}\text { I want to be an entrepreneur } \\
\text { because I have acquired the skills to } \\
\text { become one. }\end{array}$ & 1 & 2 & 3 & 4 & 5 & V32 \\
\hline 36 & $\begin{array}{l}\text { I want to be an entrepreneur } \\
\text { because I have the knowledge to } \\
\text { become one. }\end{array}$ & 1 & 2 & 3 & 4 & 5 & V33 \\
\hline 37 & $\begin{array}{l}\text { I want to be an entrepreneur because } \\
\text { I have no other means of making an } \\
\text { income. }\end{array}$ & 1 & 2 & 3 & 4 & 5 & V34 \\
\hline 38 & $\begin{array}{l}\text { I want to be an entrepreneur because } \\
\text { I tend to spot opportunities to } \\
\text { become one. }\end{array}$ & 1 & 2 & 3 & 4 & 5 & V35 \\
\hline
\end{tabular}

Note: Questions 30 to 34 test measures for entrepreneurial intention (intention to start a business within 3-5 years). V34 was found to be an outlier and attributed this to the ambiguous wording of the sentence.

intervention made a difference: those who participated in the long intervention demonstrated higher positive perceptions of entrepreneurial intent than did those who participated in the short intervention.

We included our findings using descriptive statistics for the reader's information (Table 10).

We found that those who participated in the short and long entrepreneurship education interventions demonstrated positive perceptions for entrepreneurial intention. In addition, we found that those who participated in the long intervention displayed higher levels of entrepreneurial intention than did those who participated in the short intervention. We were thus satisfied to accept our hypothesis, which was part of a full research that participants who 
TABLE 10: Descriptive statistics of increase in entrepreneurial intention by programme duration

\begin{tabular}{lcccccccc}
\hline V1 & $\boldsymbol{N}$ & Mean & Standard deviation & Standard error & $\boldsymbol{t}$-value & Pr $>\boldsymbol{t}$ & Minimum & Maximum \\
\hline LP & 381 & 4.19 & 0.83 & 0.04 & - & - \\
SP & 631 & 4.04 & 0.84 & 0.03 & - & - \\
Diff (1-2) Pooled & - & 0.1489 & 0.84 & - & 2.73 & 0.0065 \\
Diff (1-2) Satterthwaite & - & 0.1489 & - & - & 2.74 & 0.0063 & - \\
\hline
\end{tabular}

$S P$, short programme; $L P$, long programme.

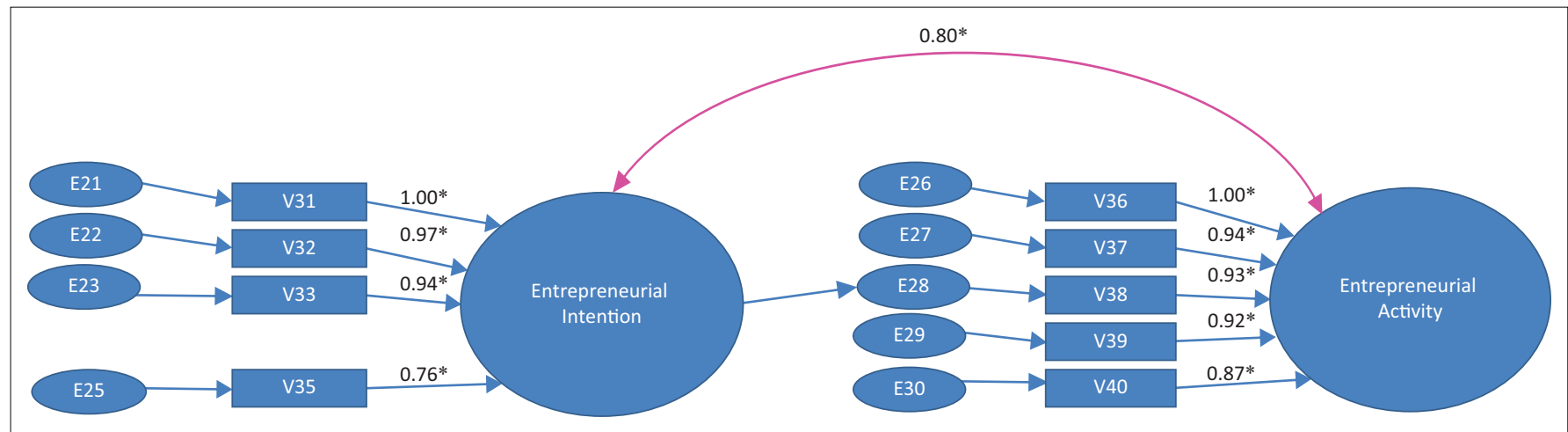

FIGURE 7: Confirmatory factor analysis on entrepreneurial activity.

TABLE 11: Entrepreneurial activity factor loadings.

\begin{tabular}{llc}
\hline Variable & Factor description & Loading \\
\hline 36 & Start entrepreneurial activity within 5 years of leaving school & 1.00 \\
37 & Most important aim of my entrepreneurial activity is to make profit & 0.94 \\
38 & $\begin{array}{l}\text { Most important aim of my entrepreneurial activity is to take } \\
\text { advantage of my skills and knowledge }\end{array}$ & 0.93 \\
39 & $\begin{array}{l}\text { Most important aim of my entrepreneurial activity is to create } \\
\text { employment }\end{array}$ & 0.92 \\
40 & $\begin{array}{l}\text { Most important aim of my entrepreneurial activity is to grow the } \\
\text { economy }\end{array}$ & 0.87 \\
\hline
\end{tabular}

Self-efficacy $\langle---->>$ Entrepreneurial Activity, loading $=0.70$.

Self-efficacy $<-. . . .-.->$ Entrepreneurial Intention, loading $=0.71$

Entrepreneurial Intention $<----->$ Entrepreneurial Activity, loading $=0.80$.

engaged in a long entrepreneurship education intervention would demonstrate higher increased positive perceptions of entrepreneurial intention than would those who participated in the short intervention.

Finally, we ran a CFA on entrepreneurial activity (see Figure 7) and found acceptable data to model fit indices.

We conducted the CFA on five factors. All factors, except for V36, demonstrated acceptable fit indices, that is, exceeded 0.5 , and were thus acceptable to us. V36 equalled 0.5 , but we decided to retain it.

In our diagram in Table 11, we show how the entrepreneurial activity factors loaded when we ran the CFA.

The CFA constructs were stated on the questionnaire as reflected in Table 12.

\section{Discussion on entrepreneurial activity}

For this construct, we recorded a $97 \%$ completion rate for the short intervention and 99\% completion rate for the long intervention. Once again, we found that most responses across the short and long intervention
TABLE 12: Questions relating to entrepreneurial activity.

\begin{tabular}{lllllllll}
\hline No. & Question & $\begin{array}{c}\text { Rank } \\
\text { 1 }\end{array}$ & Rank & Rank & Rank & Rank & Variables \\
\hline 35 & $\begin{array}{l}\text { I want to start my entrepreneurial } \\
\text { venture within 5 years of leaving }\end{array}$ & 1 & 2 & 3 & 4 & 5 & V36 \\
school. & & & & & & \\
36 & $\begin{array}{l}\text { The most important aim of my } \\
\text { entrepreneurial activity will be to } \\
\text { make a profit. }\end{array}$ & 1 & 2 & 3 & 4 & 5 & V37 \\
$37 \begin{array}{l}\text { The most important aim of my } \\
\text { entrepreneurial activity will be to } \\
\text { take advantage of my skills and } \\
\text { knowledge. }\end{array}$ & 1 & 2 & 3 & 4 & 5 & V38 \\
38 & $\begin{array}{l}\text { The most important aim of my } \\
\text { entrepreneurial activity will be to } \\
\text { create employment. }\end{array}$ & 1 & 2 & 3 & 4 & 5 & V39 \\
39 & $\begin{array}{l}\text { The most important aim of my } \\
\text { entrepreneurial activity will be to } \\
\text { grow the economy. }\end{array}$ & 1 & 2 & 3 & 4 & 5 & V40 \\
\hline
\end{tabular}

Note: Questions 35-39 test measures for entrepreneurial activity (those who see an opportunity to start a business in order to be independent or make a profit).

participation ranged in the $4-5$ cluster. We observed that all participants, whether they engaged in the short or long intervention, responded to having experienced increased perceptions of entrepreneurial activity. We also found that those who participated in the long intervention responded to having experienced higher increased perceptions of entrepreneurial activity than did those who participated in the short intervention. Figure 8 depicts the graphic representation.

We included the result found when we ran descriptive statistics. We represent those in Table 13.

We found that, though small, there was a significant difference nonetheless between those who engaged in the short and long intervention, and we were thus able to accept as valid our hypothesis that those who engaged in the long entrepreneurship education intervention would experience higher positive perceptions of entrepreneurial activity than would those who engaged in the short intervention. 


\section{Discussion on hypotheses testing}

Our study was able to validate our hypotheses with respect to self-efficacy, entrepreneurial intention and activity. Our study also demonstrated that the duration of the intervention would exert influence on the participants' perceptions.

In our full study, 16 hypotheses related to the factors linked to self-efficacy, entrepreneurial intention and activity were formulated. In running these tests, CFA and descriptive statistics, we found evidence to validate 15 of those. The one that we did reject related to the unstable factor, V34. However, our evidence showed that $80 \%$ of the participants had responded positively to the factor.

Our study found evidence to validate our view that any entrepreneurship education intervention would promote and positively influence perceptions relating to self-efficacy, entrepreneurial intention and activity. We also found evidence to support our view that the duration of the intervention would enhance the influence on such perceptions.

\section{Conclusion}

We believe that through this study we have made findings and conclusions that contribute to theory. Specifically, our contribution may bein describing the kind of entrepreneurship education intervention required in South Africa to influence the development of self-efficacy among 15-18-year-olds in basic education. We have also contributed to the understanding of how self-efficacy correlates with the development of entrepreneurial intention. Finally, we have contributed to the understanding of entrepreneurial intention and its influence on entrepreneurial activity.

Our study has also contributed to research methodology. In our study, we adapted the standardised eScan and Bandura

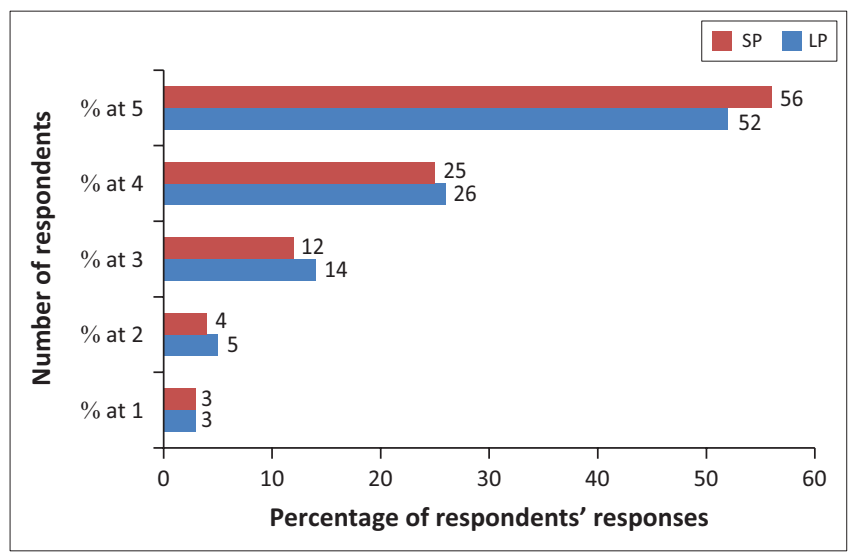

FIGURE 8: Influence on prediction of entrepreneurial activity by programme duration. SP, short programme; LP, long programme. scales for fit in the South African context. Our customisation of those two scales has contributed to the existing body of knowledge in terms of generating a reliable and valid instrument to give insights into the kind of entrepreneurship education intervention that might add value in the South African context, which is characterised by an immature state of entrepreneurship.

We also made a practical contribution through our study. Critical to why we undertook the study was the need to contribute to issues relating to curriculum revision for 15-18-year-olds in basic education. Our particular focus was to provide a compelling reason as to why entrepreneurship education should be included in the curriculum and key components of such an education. Our intention in making such practical contribution was driven by the belief that more South African youth should choose entrepreneurship as a career choice to alleviate the youth unemployment rate in South Africa.

Our practical recommendation was made to the South African Department of Basic Education (DBE). We recommended that all Grades 10-12 learners should be offered compulsory entrepreneurship education courses. In addition, through insights derived from global best practices, we recommended the phased introduction of such education. We included recommendations such as incremental implementation from Grades 10 to 12, development of educator resources, educator reskilling and an implementation plan.

We also made recommendations to JASA. Some of those recommendations included the need to revise some aspects of its programme design for better alignment with the Botha et al. model. Material to such revision would be learner mentoring, narration of success stories and redesign of some learning outcomes to actively include innovation and creativity.

Whilst we noted that there is no consensus in terms of what the ideal entrepreneurship education curriculum ought to look like, we recommended aspects such as business planning, business improvement and rescue, problemsolving, networking, finance and the management of finance, creativity and innovation, mentorship, design-based learning, reflection exercises, team development, value creation, market research and field research (Bux 2017), as these are not common knowledge areas among South African youth.

We made recommendations around the inclusion of practical experience to complement theory. We recommended the inclusion of the practical aspect that could be gained through work experience or simulated

TABLE 13: Descriptive statistics of increase in predictions of entrepreneurial activity by programme duration.

\begin{tabular}{lcccccccc}
\hline V1 & $\boldsymbol{N}$ & Mean & Standard deviation & Standard error & $\boldsymbol{t}$-value & Pr $>\boldsymbol{t}$ & Minimum & Maximum \\
\hline Long programme (LP) & 381 & 4.26 & 0.68 & 0.03 & - & - & - \\
Short programme (SP) & 630 & 4.19 & 0.68 & 0.02 & - & - \\
Diff (1-2) Pooled & - & 0.07 & 0.68 & - & 1.67 & 0.0962 & - \\
Diff (1-2) Satterthwaite & - & 0.07 & - & - & 1.66 & 0.0965 & - \\
\hline
\end{tabular}


work experience. The learners would need to prepare a report and portfolio of evidence showing that they had actually gained such experience.

We also made some policy recommendations to the DBE. This recommendation was largely focused on revision of the Grade 10-12 curriculum. We advocated for the inclusion of entrepreneurship education as a mandatory learning area. In our advocacy, we recommend that practical steps be implemented to foster the encouragement of such learners that entrepreneurship is a noble career choice. Our implementation plan included aspects such as that all Grades 10-12 learners should take entrepreneurship education with stepped learning outcomes, that this be afforded to all South African learners across all public and private education institutions, that such learning outcomes could be the JASA learning outcomes or mirror those, that the Botha et al. model should become a framework for the entrepreneurship education design, development of customised educator and learner resources for the specific context in South Africa, reskilling of educators for subject matter mastery, a support structure for educators and a monitoring and evaluation plan.

We recommended in addition that, to really understand how this could be practically implemented in South Africa, the DBE consider some of the global best practices and we suggested the Creative Entrepreneurship in Schools Project. We identified this project because it has had wide implementation (in over eight countries), and it focused on engaging a similar age group population for considering entrepreneurship as a career choice.

We did recommend that DBE make clear national policy on the subject of inclusion of entrepreneurship education into the Grade 10-12 curriculum. Key to the success of such national policy would be the clear clarification of roles and responsibilities and accountabilities of provincial and local government. In addition, we recommended that other government departments also become part of the value cluster for the implementation of such education.

We made recommendations at a national level of the South African government. Such recommendations included aspects of fostering and growing the state of entrepreneurship in South Africa, addressing the current prohibitive entrepreneurship culture in South Africa and largely reverting to the White Paper on National Strategy for the Development and Promotion of Small Business in South Africa (DTI 2005).

We also looked at Africa success stories: where, in facing contexts similar to that of South Africa at present, such African economies were able to enable and empower youth using entrepreneurship education as a catalyst to address youth unemployment. We went on to extend this to include success stories from around the world and recommend that
South Africa consider the story of the UK's Bolton Task Force Report on Small Firms (Lundstrom et al. 2001:384), as well as the story of Brazil (GEM 2012), which reported that in terms of contribution to its economy, ' $96 \%$ of the jobs and $98 \%$ of the total number of businesses in Brazil were being created by micro and small businesses' (www. endeavorbrazil.org 2014).

We concluded by recommending that, in a country where youth unemployment is high and increasing year on year, it is the responsibility of all institutions, private and public, to initiate the change. We conclude by recommending that the kind of education our youth receive might well be a good point at which to start to make the difference to youth unemployment and poverty. The same may be stated for Africa at large and we believe that our study has contributed to the dialogue.

\section{Acknowledgements}

This article is based on the $\mathrm{PhD}$ thesis of the first author at the University of Pretoria, 2017, titled 'The effect of entrepreneurship education programmes on the mind-set of South African youth' by Sara Bux, available at: http://hdl. handle.net/2263/60530.

\section{Competing interests}

The authors declare that they have no financial or personal relationships that may have inappropriately influenced them in writing this article.

\section{Authors' contributions}

S.B. was responsible for the primary research and write-up (in its entirety). J.V.V. was responsible for the supervision.

\section{Funding}

This study received funding from BankSeta.

\section{Data availability statement}

Data are available upon reasonable request to the author.

\section{Disclaimer}

The views and opinions expressed in this article are those of the authors and do not necessarily reflect the official policy or position of any affiliated agency of the authors.

\section{References}

Alain, F. \& Linan, F., 2014, The future of research on entrepreneurial intention, viewed 20 May 2016, from https://www.researchgate.net/publication/258237464.

Antonites, A. \& Govindasamy, T., 2013, 'Critical success factors of Indian entrepreneurs', The South African Journal of Entrepreneurship and Small Business Management 6, 115-133. https://doi.org/10.4102/sajesbm.v6i1.36

Aslam, T., Awan, A. \& Khan, T., 2012, An empirical study of family background and entrepreneurship as a career selection among university students of Turkey and Pakistan, viewed 30 April 2016, from http://ijbssnet.com/journals/Vol_3_No_15_ August_2012/15.pdf. 
Bandura, A., 1986, Social foundations of thought and action: A social cognitive theory, Prentice-Hall, Englewood Cliffs, NJ.

Bandura, A., 1997, Self-efficacy: The exercise of control, Freeman and Company, New York.

Barua, P., 2013, 'The moderating role of perceived behavioural control: The literature criticism and methodological considerations', International Journal of Business and Social Science 4(10), 57-59.

Bidin, Z., Shamsudin, F.M. \& Othman, Z., 2012, Applying theory of planned behaviour on entrepreneurial intention of Malay accounting students in Malaysia, viewed 20 May 2016, from https://www.researchgate.net/publication/277154751.

Bignotti, A., 2013, 'Factors relating to entrepreneurial career choice of secondary school students', University of Pretoria, South Africa.

Botha, M., Van Vuuren, J.J. \& Kunene, T., 2015, 'An integrated entrepreneurial performance model focusing on the importance and proficiency of competencies for start-up and established SMEs', South African Journal of Business Management 46(3), 55-66. https://doi.org/10.4102/sajbm.v46i3.101

Bux, S., 2016, The effect of entrepreneurship education programmes on the mind-set of South African youth, University of Pretoria.

De Berg, C.L. \& Eimer, P.C., 2012, Social enterprise and socially-responsible business: A global education program linking teens to higher education and the private sector viewed 04 March 2016, from http://www.ijbhtnet.com/journals/Vol_2_No_1_ January_2012/5.pdf.

Fayolle, A., 2005, 'Evaluation of entrepreneurship education: Behaviour performing or intention increasing?', International Journal of Entrepreneurship and Smal Business 2(1), 89-98. https://doi.org/10.1504/IJESB.2005.006072

Garud, R. \& Guiliani, A.P., 2013, 'A narrative perspective on entrepreneurial opportunities', Academy of Management Review 38(1), 157-160. https://doi. org/10.5465/amr.2012.0055

Gibb, A., 2005, Towards the entrepreneurial university, entrepreneurship education as a lever for change, Policy Paper for the National Council for Graduate Entrepreneurship (NCGE), Birmingham.

Herrington, M., 2006, The 2006 South African GEM report, viewed 14 April 2015, from http://www.uct.ac.za/faculties/gsbhtml.

Karali, S., 2013, The impact of entrepreneurship education programs on entrepreneuria intentions: An application of the theory of planned behaviour, Erasmus School of Economics, Rotterdam.
Kolvereid, L., 1996, 'Organisational employment versus self-employment: Reasons for career choice intentions', Entrepreneurship Theory and Practice 20(3), 23-31. https://doi.org/10.1177/104225879602000302

Kozlinska, I., 2014, Linkages between entrepreneurial education and entrepreneurship evidence from two post-transition countries, Turku School of Economics, University of Turku, Turku.

Krueger, A., 2000, The evolution of entrepreneurs' intentions, viewed 19 October 2014, from http://www.books.google.co.za/books/isbn/html.

Lin, C.H.F. \& Chen, C.S., 2010, Application of theory of planned behaviour on a study of workplace dishonesty, LAC S IT Press, Philippines.

Lundstrom, A. \& Stevenson, L., 2001, Entrepreneurship policy for the future, Swedish Foundation for Small Business Research, Stockholm.

Malebana, M.J. \& Swanepoel, E., 2014, 'The relationship between exposure to entrepreneurship education and entrepreneurial self-efficacy', South African Business Review 18(1), 1-26.

Moos, M., 2016, 'Determining the relationship between entrepreneurial self-efficacy, personality and gender differences', Southern African Institute of Management Scientists 28, 469-497.

Morris, M.H., Webb, J.W., Fu, J. \& Singhai, S., 2013, 'A competency-based perspective on entrepreneurship education: Conceptual and empirical insights', Journal of Small Business Management 51(3), 352-369. https://doi.org/10.1111/jsbm.12023

Souitaris, V., Zerbinati, S. \& Al-Laham, A., 2007, 'Do entrepreneurship programme raise entrepreneurial intention of science and engineering students? The effect of learning, inspiration and resources', Journal of Business Venturing 22(4), 566-591. https://doi.org/10.1016/j.jbusvent.2006.05.002

Steenekamp, A.G., Van der Merwe, S.P. \& Athayde, R., 2011, 'An investigation into youth entrepreneurship in selected South African secondary schools: An exploratory study', Southern African Business Review 15, 46-75.

Urban, B., 2004, Understanding the moderating effect of culture and self-efficacy on entrepreneurial intention, viewed 10 December 2015, from http://repository.up. ac.za/bitstream/handle/2263/27545/00thesis.pdf?sequence $=1$.

Urban, B., 2016, Solving unemployment in South Africa, viewed 15 February 2016 from https://www.wits.ac.za/news/latest-news/research-news/2016/2016-01/ solving-unemployment-in-south-africa.html.

Viviers, S., Solomon, G. \& Venter, C., 2013, 'Entrepreneurial intentions and behaviours of South African University students', The Southern African Journal of Entrepreneurship and Small Business Management 6(145), 210-230. 